\title{
MANAJEMEN BISNIS BAGI PENGELOLA BUMDES KABUPATEN PANDEGLANG
}

\author{
Abdurrohman', Anis Fuad Salam², Dwi Fitrianingsih ${ }^{3}$, Indar Riyanto ${ }^{4}$ \\ M. Atep Effiana Taufik ${ }^{5}$ \\ Dosen Prodi Akuntansi, Sekolah Tinggi Ilmu Ekonomi Banten ${ }^{1,3,5}$, \\ Dosen Prodi Akuntansi, Sekolah Tinggi Ilmu Ekonomi Banten ${ }^{2, \& 4}$
}

Email : oman. abdurrohman24@gmail.com ${ }^{1}$

\begin{abstract}
ABSTRAK
Tujuan pelaksanaan pengabdian ini ialah menyampaikan pengetahuan dan keterampilan dalam mengelola bisnis bagi pengelola BUMDES Kabupaten Pandeglang.Kegiatan ini dilaksanakan dalam rangka membantu menyelesaikan permasalahan bagi pengelola BUMDES dalam melaksanakan manajemen bisnisnya.Sebelum kegiatan pengabdian berlangsung dilakukan diskusi terlebih dahulu dengan Dinas Pemberdayaan Masyarakat dan Pemerintahan Desa (DPMPD) Kabupaten Pandeglang terkait dengan permasalahan yang dihadapi oleh pengelola BUMDES yang dituangkan dalam bentuk materi pelatihan yang diselenggarakan oleh DPMPD Kabupaten Pandeglang kerjasama dengan Sekolah Tinggi Ilmu Ekonomi (STIE) Banten. Bentuk kegiatan pengabdian ini yaitu pelatihan berbagai materi terkait dengan permasalahan yang ada di BUMDES yaitu (1) Peta Jalan BUMDES Sukses, (2) Kewirausahaan, (3) Kepemimpinan, (4) Pemasaran, (5) Kerjasama, dan (6) Tata Kelola Keuangan BUMDES yang dihadiri oleh 50 pengelola BUMDES yang dipilih oleh DPMPD Kabupaten Pandeglang. Dalam pelaksanaan materi pelatihan, disisipkan praktek bagaimana cara memimpin, memasarkan, membuat kerjasama dan praktek pembukuan laporan keuangan. Selanjutnya untuk lebih memantapkan materi disesi terakhir dibuka tanya jawab dan diskusi. Saran dari kegiatan ini adalah perlu adanya pendampingan lanjutan dilapangan dan kontrol pelaksanaan kegiatan pengelolaan BUMDES.
\end{abstract}

Kata Kunci : Tata Kelola Keuangan BUMDES

\section{ABSTRACT}

The purpose of this service is to convey knowledge and abilities in managing business for the BUMDES manager of Pandeglang Regency. This activity is carried out in order to help solve problems for BUMDES managers in carrying out business management. Before the community service activities take place, discussions were held with the Pandeglang District Community Empowerment and Village Administration (DPMPD) Office in relation to the problems faced by the BUMDES managers which would later be contained in the form of training materials organized by DPMPD Pandeglang Regency in collaboration with the College of Economics (STIE) ) Banten. The form of this community service activity is training on various materials related to problems in BUMDES, namely (1) BUMDES Success Road Map, (2) Entrepreneurship, (3) Leadership, (4) Marketing, (5) Cooperation, and (6) Governance BUMDES finances attended by 50 BUMDES managers selected by DPMPD Pandeglang Regency. In the implementation of training materials, the practices of how to lead, market, make cooperation and practice financial bookkeeping are inserted. Furthermore, to further strengthen the material in the final session, questions and answers and discussions were opened. Suggestions from this activity are the need for further assistance in the field and control of the implementation of BUMDES management activities.

Keywords:, BUMDES Financial Governance 


\section{PENDAHULUAN}

Perubahan paradigma Desa dari desa lama sebagai objek pembangunan menjadi desa baru yaitu subjek pembangunan. UU No. 6 Tahun 2014 tentang Desa memberikan gambaran bahwa pertama, pemberian kewenangan berdasarkan azas Rekognisi dan Subsidiaritas, dimana rekognisi berarti pengakuan dan penghormatan terhadap keberadaan (eksistensi) desa, sementara subsidiaritas berarti penggunaan kewenangan skala lokal. Gambaran yang kedua yaitu kedudukan desa sebagai pemerintahan berbasis masyarakat, yaitu campuran dari komunitas yang mengatur dirinya sendiri (self governing communitiy) dan pemerintahan lokal (local self government).Desa paska UU Desa memiliki (1) Kewenangan, (2) Wilayah, dan (3) Dana.

Dalam kaitannya dengan dana desa, Desa diberikan kewenangan dalam pengelolaan dana desa sesuai dengan Permendagri No. 113 Tahun 2014 yang diperbaharui Permendagri No. 20 Tahun 2018 tentang pengelolaan keuangan desa. Agar dana desa tersebut bisa dikelola dengan baik, salah satunya bisa dimanfaatkan dalam pengelolaan usaha dan dapat menambah pendapatan asli desa, maka desa bisa membentuk badan usaha yang disebut dengan BUMDES.

Pengertian BUMDES menurut UU No. 6 Tahun 2014 tentang Desa adalah badan usaha yang seluruh atau sebagian modalnya dimiliki oleh desa melalui penyertaan secara langsung yang berasal dari kekayaan desa yang dipisahkan guna mengelola aset, jasa pelayanan, dan usaha lainnya untuk sebesar-besarnya kesejahteraan masyarakat desa. Sejak tahun 2014 BUMDES tiba-tiba menjadi populer dan dibahas oleh banyak orang. Banyak orang percaya bahwa BUMDES ini adalah penyelamat perekonomian Indonesia yang kondisinya masih maju mundur.

Berbicara tentang status hukum BUMDES, Kemendesa dalam naskah penjelasan UU Desa menguraikan bahkwa kedudukan BUMDES tidak dapat disamakan dengan badan hukum seperti PT, CV, atau Koperasi karena dasar pembentukan BUMDES adalah peraturan, bukan Akta.BUMDES memiliki tujuan khusus, yakni kepemilikan secara utuh dan total atas bisnis oleh pemerintah desa untuk tujuan kepentingan rakyat, dalam hal ini masyarakat desa.

Jumlah desa di Kabupaten Pandeglang yaitu 326 desa, dan menurut data dari Dinas Pemberdayaan Masyarakat dan Pemerintahan Desa (DPMPD) Kabupaten Pandeglang, dari 326 desa tersebut dapat dipastikan semuanya sudah membentuk BUMDES sesuai arahan Bupati Pandeglang. Hanya saja permasalahannya apakah BUMDES tersebut sudah berjalan usahanya sesuai dengan yang diinginkan?Kenyataannya tidak dapat dipugkiri bahwa belum semua BUMDES yang ada sudah berjalan usahanya.

Dalam menjalankan usahanya setidaknya ada beberapa hal secara keilmuan materi yang harus dikuasai oleh pengelola BUMDES, yaitu diantaranya (1) Peta Jalan BUMDES Sukses,

Kewirausahaan, (3) Kepemimpinan, (4) Pemasaran, (5) Kerjasama, dan (6) Tata Kelola Keuangan BUMDES.Untuk itu DPMPD Kabupaten Pandeglang bekerjasama dengan Sekolah Tinggi Ilmu Ekonomi (STIE) Banten membuat kegiatan pengabdian dengan menyelenggarakan pelatihan manajemen bisnis bagi pengelola BUMDES Kabupaten Pandeglang.

Menurut Astim Riyanto dan Arifah (2000:3) "Wiraswasta" atau "pengusaha" diambil dari bahasa perancis entrepreneur yang pada mulanya berarti pemimpin musik atau pertunjukan lainnya. Dalam ilmu ekonomi seorang pengusaha berarti seorang pemimpin ekonomi yang memiliki kemampuan untuk mendapatkan peluang secara berhasil memperkenalkan mata dagangan baru, teknik baru, sumber pemasukan baru, serta pabrik, peralatan, manajemen, tenaga buruh yang diperlukan, dan mengorganisasikannya kedalam suatu teknik pengoperasian perusahaan. Permasalahan yang terjadi, 
pengelola BUMDES belum mempunyai jiwa entrepreneur, sehingga diperlukan adanya pelatihan tentang bagaimana memiliki jiwaentrepreneur.

(Kartono, 2016)berpendapat bahwa kepemimpinan merupakan salah satu relasi dan pengaruh antara pemimpin dengan yang dipimpin.Kepemimpinan tersebut muncul dan berkembang sebagai hasil dari interaksi otomatis antara pemimpin dengan orang-orang yang dipimpinnya.Dalam hal kepemimipinan BUMDES, bahwa pengelola diharapkan mempunyai jiwa kepemimpinan sehingga dapat menggerakan tim yang bergabung dalam usahanya menuju tujuan yang akan dicapai dengan baik.

Definisi Pemasaran menurut (Kotler, 2013)adalah suatu proses sosial yang didalamnya individu dan kelompok mendapatkan apa yang mereka butuhkan dan inginkan dengan menciptakan, menawarkan, dan secara bebas mempertukarkan produk yang bernilai dengan pihak lain.Dalam kaitannya dengan BUMDES jiwa pemasaran harus dimiliki oleh pengelola BUMDES, tantangan saat ini adalah bagaimana pemasaran usaha BUMDES bisa berjalan dengan penerapan teknologi sesuai dengan yang berlaku dijaman saat ini.

(Hafsah, 2002a)menyebut kerjasama ini dengan istilah kemitraan, yang artinya adalah suatu strategi bisnis yang dilakukan oleh dua pihak atau lebih dalam jangka waktu tertentu untuk meraih keuntungan bersama dengan prisip saling membutuhkan dan saling membesarkan. Pengelola BUMDES tidak bisa bekerja sendiri, melainkan butuh berbagai pihak untuk mencapai tujuan, untuk itu dalam kegiatan pelatihan ini, pengelola BUMDES diajarkan bagaimana caranya menjalin kerjasama dan langsung praktek membuat surat kerjasama dengan para pihak.

Menurut Ikatan Akuntan Indonesia (PSAK, 2013) bahwa definisi mengenai laporan keuangan terdiri dari proses laporan keuangan pada umumnya terdiri dari neraca, laporan laba rugi, laporan perubahan ekuitas, laporan posisi keuangan, catatan dan laporan lain serta materi akan penjelasan yang merupakan bagian integral dari laporan keuangan.Dalam kaitannya tentang laporan keuangan BUMDES, pengelola BUMDES diharapkan mampu membuat laporan keuangan sesuai dengan Standar Akuntansi Keuangan.Untuk itu dalam pelatihan ini, selain materi tentang bagaimana menyusun laporan keuangan BUMDES, dibuat pula praktek membuat laporan keuangan BUMDES.

Pendekatan yang dilakukan sebagai tawaran menyelesaikan masalah dalam kegiatan pengabdian masyarakat ini adalah dengan metode sebagai berikut : (1) Metode ceramah, yaitu memberikan pemaparan materi tentang Peta Jalan BUMDES Sukses, Kewirausahaan, Kepemimpinan, Pemasaran, Kerjasama, dan Tata Kelola Keuangan BUMDES. (2) Metode Simulasi, yaitu memberikan contoh tentang materi-materi yang diberikan dan sekaligus mempraktekannya. (3) Metode diskusi, yaitu memberikan kesempatan kepada pengelola BUMDES untuk menanyakan tentang materi yang sudah diberikan namun ada yang kurang difahami atau sebaliknya. (4) Program Pendampingan, dengan tujuan agar memberikan solusi konkrit kepada pengelola BUMDES dalam menghadapi permasalahan yang terjadi pada saat pelaksanaan usahanya.

\section{METODE PELAKSANAAN}

Pelaksanaan kegiatan pengabdian ini selama 3 hari yaitu hari kamis sampai dengan sabtu, 17-19 Oktober 2019 bertempat di Hotel Mutiara Carita, Labuan Pandeglang. Adapun pelaksanaan kegiatan dibagi kedalam beberapa tahap, antara lain : (1) Tahap persiapan, pada tahap persiapan, pihak STIE Banten berkoordinasi dengan penyelenggara kegiatan DPMPD Kabupaten Pandeglang perihal persiapan apa saja yang dibutuhkan terutama terkait dengan peserta kegiatan yaitu pengelola BUMDES, dan permasalahan yang dialami BUMDES 
yang ada di Kabupaten Pandeglang. Dari permasalahan tersebut diperoleh kesimpulan tentang materi pelatihan yang akan dilaksanakan pada kegiatan pengabdian serta penentuan peserta yang diundang dan tempat. (2) Tahapan berikutnya adalah tim pengabdian dari STIE Banten mempersiapan materi pelatihan dalam bentuk power point untuk presentasi, soal latihan untuk simulasi dan post test. (3) selanjutnya tim pengabdian melakukan pelatihan dan pendampingan. Tenaga ahli dibidang masing-masing materi sudah disiapkan yaitu dari tim pengabdian STIE Banten. (4) Tahap terakhir disetiap sesi materi dilakukan diskusi dan post test guna mengetahui sejauh mana pemahaman peserta pelatihan dalam menyimak setiap materi yang diberikan.

\section{HASIL DAN PEMBAHASAN}

Sebelum kegiatan pengabdian dilaksanakan, dimulai dengan tahapan diskusi dan koordinasi dengan pihak DPMPD Kabupaten Pandeglang. Hasil diskusi diperoleh bahwa BUMDES yang sudah dibentuk disetiap desa di Kabupaten Pandeglang masih belum maksimal berjalan, bahkan ada yang tidak beroperasi sama sekali, hal ini terjadi karena ketidaktahuan pengelola BUMDES dalam menjalankan bisnisnya. Untuk itu diperoleh kesimpulan bahwa timpengabdian bekerjasama dengan DPMPD melakukan pelatihan Manajemen Bisnis Bagi Pengelola BUMDES dengan menyampaikan materi tentang Peta Jalan BUMDES Sukses, Kewirausahaan, Kepemimpinan, Pemasaran, Kerjasama, dan Tata Kelola Keuangan BUMDES.Pelatihan ini dilaksanakan terbatas hanya 50 peserta BUMDES dengan harapan dari kegiatan ini dapat memberikan solusi atas permasalahan yang yang dihadapi oleh masing-masing pengelola BUMDES sehingga pengelola BUMDES dapat menjalankan kegiatan usahanya dengan baik.
Kegiatan pengabdian ini berjalan dengan baik dan lancar, dimulai dihari pertama pembukaan oleh Wakil Bupati Pandeglang dan sambutan oleh Plt. Kepala Dinas DPMPD Kabupaten Pandeglang.Selanjutnya penyampaian materi yang dilakukan oleh tim pengabdian sampai dengan hari ketiga dengan materi yang disampaikan yaitu tentang :(1)Mulai dari bagaimana peta jalan BUMDES agar bisa sukses, tujuan materi ini adalah agar pengelola mengetahui seluk beluk tentang BUMDES dan bagaimana caranya agar BUMDES yang dikelolanya bisa sukses. (2) Materi berikutnya tentang kewirausahaan, pada materi ini dibedah tentang jiwa kewirausahaan pengelola BUMDES agar bisa menjalankan dengan baik. Karena BUMDES ini bentuknya usaha, maka penting sekali bagi pengelola untuk memiliki jiwa kewirausahaan. (3) Selanjutnya materi kepemimpinan, pada usaha BUMDES, pengelola pasti mempunyai tim yang harus dipimpinnya, untuk itu materi ini sangat penting diperoleh oleh pengelola guna menumbuhkan jiwa kepemimpinannya. Pada materi ini dilakukan simulasi bagaimana memimpin sebuah tim. (4) Dilanjutkan dengan materi pemasaran, BUMDES akan jalan dengan baik manakala konsep yang sudah direncanakan bisa direalisasikan. Realisasi kegiatan ini butuh yang namanya pemasaran.Seiring dengan perkembangan teknologi saat ini, materi pemasaran yang diberikan yaitu bagaimana bisa menjalankan pemasaran dengan teknologi, misalnya melalu media sosial (Facebook, WhatsApp, Instagram, dan lain-lain), sekaligus simulasi bagaimana pemasaran menggunakan media sosial tersebut bisa dijalankan. (5) Berikutnya materi tentang kerjasama, BUMDES pasti akan membutuhkan kerjasama dari pihak lain, untuk itu materi ini penting juga disampaikan bagaimana menjalin kerjasama yang baik dan tepat sasaran sesuai dengan bidang usaha BUMDES masing-masing. Dalam materi ini disampaikan simulai pembuatan surat perjanjian kerjasama. (6) Yang tak kalah 
menarik dari semua materi pelatihan adalah tentang tata kelola keuangan BUMDES. Pada materi ini dibahas tentang laporan keuangan. Ini menjadi penting karena tanpa adanya pembukuan laporan keuangan, maka keuangan BUMDES tidak akan terkontrol dengan baik. Disesi akhir materi ini dibuat simulasi dan praktek pembuatan pembukuan laporan keuangan.

Peserta pelatihan pada pengabdian ini sangat antusias memberikan pertanyaan terkait dengan beberapa materi yang disampaikan, karena materi ini erat hubungannya dengan kegiatan yang mereka jalankan setiap harinya. Dari hasil diskuskusi diperoleh bahwa sebagian besar peserta pelatihan belum memahami tentang usaha BUMDES seperti apa, cara memimpin tim, cara memasarkan usahanya, cara melakukan kerjasama dengan berbagai pihak terkait dan cara melakukan pembukuan laporan keuangan dengan baik. Sebagian besar melakukannya dengan cara "yang penting jalan usahanya", padahal cara tersebut belum tentu akan menghasilkan usaha yang sukses karena untuk menjadi usaha sukses perlu belajar baik dari teori ataupun pengalaman dan praktek.

Secara keseluruhan kegiatan pelatihan Manajemen Bisnis Bagi Pengelola BUMDES Kabupaten Pandeglang dalam hal pengabdian berjalan dengan baik dan sesuai dengan tujuan yang ditetapkan sebelumnya, hal ini terbukti dengan seluruh materi kegiatan yang direncanakan sudah tersampaikan dengan baik kepada peserta, bahkan dengan simulasi dan praktek dibeberapa materi juga telah disampaikan. Antusias peserta terlihat ketika penyampaian materi, mereka benarbenar menyimak dan menyampaikan pertanyaan untuk didiskusikan.Dan sebagai masukan dari peserta, mereka menginginkan adanya pelatihan lanjutan dan pendampingan di masing-masing BUMDES.

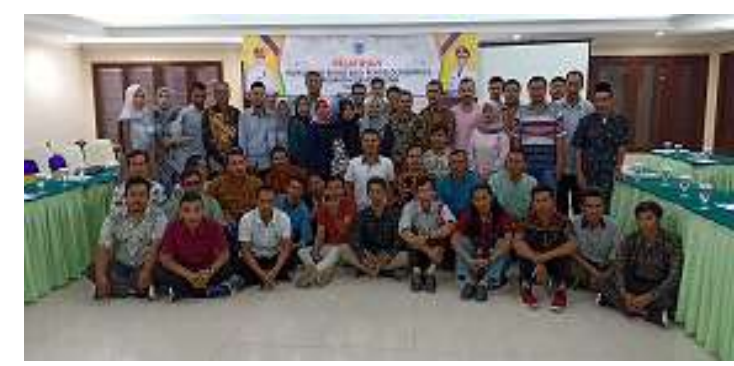

Gambar 1. Foto bersama peserta pelatihan

\section{KESIMPULAN DAN SARAN}

Berdasarkan hasil kegiatan yang dilaksanakan, bahwa peserta mulai memahami tentang bagaimana usaha harus dilakukan di BUMDES, bagaiman cara memimpin tim ditempat usahanya, bagaimana cara memasarkan usahanya, bagaimana cara melakukan kerjasama dengan berbagai pihak terkait dan bagaimana cara melakukan pembukuan laporan keuangan dengan baik.Sehingga peserta dapat mempraktekannya pada kegiatan keseharian di lapangan dengan usaha pada BUMDES nya masing-masing.

Kegiatan ini sangat bagus untuk dijalankan dan difasilitasi oleh PEMDA Kabupaten yang memiliki BUMDES karena tidak sedikit BUMDES yang sudah didirikan belum mengetahui bagaimana proses menjalankan bisnis BUMDES sesuai dengan peraturan yang ada.

\section{DAFTAR PUSTAKA}

Hafsah, M. J. (2002a). Kemitraan Usaha: Konsepsi dan Strategi. In Pustaka Sinar Harapan.

https://doi.org/10.1017/CBO9781107 415324.004

Hafsah, M. J. (2002b). Kemitraan Usaha. Pustaka Sinar Harapan. https:/ / doi.org/10.1017/CBO9781107 415324.004

Kartono, K. (2016). Pemimpin dan Kepemimpinan, Apakah Kepemimpinan Abnormal Itu? In Rajawali Pers.

Kotler. (2013). Manajemen Pemasaran Jilid 2. In Penerbit Erlangga.

PSAK. (2009). Pernyataan Standar 
Akuntansi Keuangan No.1. In Penyajian Laporan Keuangan.

PSAK. (2013). Pernyataan Standar Akuntansi Keuangan 1 (revisi 2009) (Statement of Financial Accounting Standards). Ikatan Akuntansi Indonesia. Ramanda, A. S. (2018). Penerapan PSAK No . 1 Tentang Penyajian Laporan Keuangan pada PT. LMI. Festival Riset Ilmiah Manajemen \& Akuntansi.

Riyanto, A. (2012). PEMAHAMAN UNDANG-UNDANG NOMOR 14 TAHUN 2008 TENTANG KETERBUKAAN INFORMASI PUBLIK. Jurnal Hukum \& Pembangunan.

https:/ / doi.org/10.21143/jhp.vol42.n $\mathrm{o} 4.270$
Savitri, E., Andreas, A., \& Diyanto, V. (2019). Peningkatan pendapatan asli desa melalui pembinaan revitalisasi BUMDes dan tata kelola dana desa. Unri Conference Series: Community Engagement.

https:/ / doi.org/10.31258/ unricsce.1.6 06-613

Widiastuti, H., Putra, W. M., Utami, E. R., \& Suryanto, R. (2019). Menakar tata kelola badan usaha milik desa di Indonesia. Jurnal Ekonomi Dan Bisnis. https://doi.org/10.24914/jeb.v22i2.24 10

Suryanto, Rudy. 2018. Peta Jalan BUMDES Sukses.Yogyakarta: PT. Syncore Indonesia. 